delinquent heading towards a life of crime. Maternal rejection can also lead to perversion such as homosexuality, or finally to neurosis.

In examining our culture and methods of investigating it, Kardiner discusses the work of Freud and Kinsey. He gives one of the best commentaries on Kinsey's work which have so far been published and, since he has done considerable anthropological work, is able to draw on his experiences to check his conclusions. Far from being purely negative, Kardiner's criticisms enable him to give sensible remedies for many of the troubles which endanger modern civilizations. His book is an interesting one and well worth reading for its forthright views, although not every psychiatrist will agree with them. It is a pity that it is not provided with a better index.

Dr. D. J. West's book on "Homosexuality" is more of a popular medical one and should be easily comprehensible to the non-medical reader. He gives a careful outline of every aspect of homosexuality. It is considered in different communities, including our own, and discussed from the point of view of different types with their effect in creating legal and social problems. Two 'typical' cases are given.

Dr. West examines the influence of the endocrine glands, inheritance and psychological factors in causation. He discusses the relationship of homosexuality to mental abnormality and concludes his work with a somewhat sketchy chapter on treatment and prevention. This suggests that he has not had much practical experience in the therapy of the homosexual.

Medically this is not a controversial book, and it is easy to agree with nearly all that he says ; in fact, it is what many psychiatrists have been preaching for the past two decades. His outlook, however, is generous, kindly and reasonable, as one would expect from a medical man educated in psychiatry. The adverse criticism one is inclined to make is that he is over-cautious regarding treatment, which is well worth while in the less-severe cases. There are an excellent index and a long list of a hundred and sixty references in the bibliography. There is also a list of novels which have homosexuality as a subject.

Clifford Allen

\section{OUTLINE OF PARASITOLOGY}

Introduction to Parasitology, with Special Reference to the Parasites of Man

By Prof. Asa C. Chandler. Ninth edition. Pp. xiv + 800. (New York: John Wiley and Sons, Ine.; London: Chapman and Hall, Ltd., 1955.) 68s. net.

$\mathrm{T}$ HE ninth edition of this book, which began its successful career as long ago as 1918, reflects on every page the remarkable advances in knowledge that have so greatly increased our control of animals parasitic in man and other hosts. The book has always been one of the most readable of all books on parasitology. Its author, Prof. Asa C. Chandler, has the gift of the graphic and imaginative phrase; he can put, often in a simple arresting sentence or two, the complex relationships of the parasite and its environment; and man, who has good reasons for thinking that he has conquered some, at any rate, of his parasites, is warned against patting himself too complacently on the back. "In spite of spectacular advances in our struggle with parasites," Chandler says, "it is obvious . . that the battle is far from won. In 1947 Stoll made the startling estimate that there are in the world to-day 2,200 million helminthic infections [of man]-enough for one for every inhabitant [of the world] if they were evenly distributed". Nor is the author concerned with human parasites alone. He has extended, in this edition, the text that dealt in earlier editions with the parasites of domesticated animals. $\mathrm{He}$ also discusses the spirochaetes, rickettsias and filterable viruses that are transmitted to man by arthropods. A number of chapters or sections have been entirely re-written, and changes have been made on every page. These changes are the measure of the advances that have been made since the eighth edition appeared in 1949 .

This, therefore, is not a reprint of a formerly successful book. Although the general plan of the book has not been substantially altered, the reader is given a new and up-to-date account of this subject, the importance of which the author so graphically describes in his introduction. The illustrations, formerly not adequate for so valuable a book, have now been greatly improved. They have, no doubt, enabled the author to lighten the text by trans. ferring to the illustrations much of the morphological detail that some readers often find rather heavy going. Besides, it is precisely here, in conjunction with the drawings themselves, that one finds this kind of detail most convenient. Mr. George Newman, of the University of Texas Medical School, who drew most of the new illustrations, is to be congratulated on his work.

Another feature of the book is the fact that classification and taxonomy are given only in so far as they help the student to understand the general relationships of the major groups of parasites; but simple keys for the identification of arthropods are given, and these are set in small type, so that they can be omitted if the reader wishes to do this. The emphasis is on the biological aspects of the subjecton life histories, epidemiology, host-parasite relationships and the prineiples on which treatment and prevention are based.

References to the literature are given at the ends of the chapters, not all together at the end of the book, as many readers would prefer. A list of journals and books from which further information can be obtained will help the reader who is not familiar with the literature. The make-up of the book has certainly now acquired a new look; it is brighter and generally more attractive to read. This edition will undoubtedly hold for this book the place that former editions have given it.

G. LAPAGE

\section{MODERN DAIRY FARM PRACTICE}

\section{Dairy Cattle}

Selection, Feeding, and Management. By Prof. William Wodin Yapp and Prof. William Barbour Nevens. Fourth edition. (Wiley Farm Series.) Pp. xii 420. (New York : John Wiley and Sons, Inc.; London: Chapman and Hall, Ltd., 1955.) 38s. net.

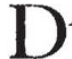

AIRY husbandry, depending on many branches of biology, changes as these sciences develop. During the past two decades these changes have bcen rapid and sometimes revolutionary in character. For example, before the Second World War artificial 